\title{
KOSAKATA BUDAYA TRADISI PENANGKAPAN KOTEKLEMA DI LAMALERA DALAM NOVEL "SUARA SAMUDRA, CATATAN DARI LAMALERA" SEBAGAI SALAH SATU ALTERNATIF PENGAYAAN KOSAKATA BAHASA INDONESIA
}

\author{
(THE CULTURAL VOCABULARY IN THE TRADITION OF CAPTURING THE \\ KOTEKLEMA IN LAMALERA IN THE NOVEL OF "SUARA SAMUDRA, CATATAN \\ DARI LAMALERA", AS ONE OF THE ALTERNATIVE OF INDONESIAN \\ VOCABULARY ENRICHMENT)
}

\author{
Nining Nur Alaini \\ Kantor Bahasa NTB \\ Jalan dr. Soejono, Kelurahan Jempong Baru, Kecamatan Sekarbela, Mataram \\ Telepon: (0370)6647388, Faksimile: (0370)623539 \\ Pos-el: nining_ismankirono@yahoo.com
}

Diterima; 17 Mei 2018; Direvisi: 15 Oktober 2018; Disetujui: 24 November 2018

\begin{abstract}
Abstrac
The three local languages mentioned in the National Language Policy formulated in the Language Politics seminar organized by the Language Center (now the Agency for Language Development and Development) in 1999 function as a language symbols including a symbol of regional identity, and a symbol of regional pride; a mean of communication in the family and local communities, and a mean of supporting regional culture and as a supporter of regional literature and Indonesian literature. As a means of supporting the Indonesian language, regional languages have a dominant role in enriching the Indonesian vocabulary. This paper will describe the cultural vocabulary in the tradition of capturing the koteklema in Lamalera in the novel of "Suara Samudra, Catatan dari Lamalera", as one of the alternative of Indonesian vocabulary enrichment. The novel of "Suara Samudra, Catatan dari Lamalera", by Maria Matildis Banda, reveals a cliché theme often appears and is raised in Indonesian novels about the relationship of two lovers due to social status differences. The novel is interesting as it is written in a traditional village setting, tradition and culture of fishing and whaling in Lamalera. This novel is an ethnographic novel that presents the traditions and culture of Lamalera through the physical and cultural background of fishermen in Lamalera. Maria Matildis Banda conveys local color through literature. His language, diction, and power of speaking in a local dialect enrich the literary treasures of Indonesia. This condition is one of the reasons for the importance of 'adopting' the registers in the novel into the Indonesian vocabulary, so that Indonesian language can further develop itself in order to play a maximum role as a means of communication in various domains of the usage, as well as play an increasingly steady role as a language amplifier for an identity and character of the nation.
\end{abstract}

Keywords: cultural vocabulary, vocabulary enrichment, and nation character 


\begin{abstract}
Abstrak
Tiga fungsi bahasa daerah yang disebutkan dalam Kebijakan Bahasa Nasional yang dirumuskan dalam seminar Politik Bahasa yang diselenggarakan oleh Pusat Bahasa (sekarang Badan Pengembangan dan Pembinaan Bahasa) pada tahun 1999, fungsi bahasa daerah meliputi lambang identitas daerah; lambang kebanggaan daerah; alat perhubungan di lingkungan keluarga dan masyarakat daerah; sebagai sarana pendukung budaya daerah dan bahasa Indonesia; dan sebagai pendukung sastra daerah dan sastra Indonesia. Sebagai sarana pendukung bahasa Indonesia, bahasa daerah memiliki peran yang dominan dalam memperkaya kosakata bahasa Indonesia.Tulisan ini akan mendeskripsikan kosakata budaya dalam tradisi penangkapan koteklema di Lamalera dalam novel "Suara Samudra, Catatan dari Lamalera", sebagai salah satu alternatif pengayaan kosakata bahasa Indonesia. Novel "Suara Samudra, Catatan dari Lamalera", karya Maria Matildis banda ini, mengangkat tema klise yang seringkali muncul dan diangkat dalam novel-novel Indonesia tentang hubungan dua anak manusia yang tidak direstui karena perbedaan status sosial. Novel ini menjadi menarik, manakala ditulis dengan latar desa, tradisi dan budaya nelayan dan penangkapan ikan paus secara tradisional di Lamalera. Novel ini merupakan novel etnografis yang menghadirkan tradisi dan budaya Lamalera melalui latar fisik dan budaya nelayan di Lamalera. Maria Matildis Banda menyampaikan warna lokal melalui sastra. Bahasa, diksi, dan kekuatannya berbicara dalam dialek lokal memperkaya khazanah sastra Indonesia. Kondisi ini merupakan salah satu alasan pentingnya 'mengadopsi' register-register dalam novel tersebut ke dalam kosakata bahasa Indonesia, sehingga bahasa Indonesia dapat semakin mengembangkan dirinya agar dapat berperan secara maksimal sebagai sarana komunikasi dalam berbagai ranah pemakainya, serta semakin mantap berperan sabagai bahasa penguat identitas dan karakter bangsa.
\end{abstract}

Kata Kunci: kosakata budaya, pengayaan kosakata, dan karakter bangsa 


\section{Latar Belakang}

Tiga fungsi bahasa daerah yang disebutkan dalam kebijakan bahasa nasional yang dirumuskan dalam seminar Politik Bahasa yang diselenggarakan oleh Pusat Bahasa (sekarang Badan Pengembangan dan Pembinaan Bahasa) pada tahun 1999, meliputi lambang identitas daerah, lambang kebanggaan daerah, alat perhubungan di lingkungan keluarga dan masyarakat daerah, dan sebagai sarana pendukung budaya daerah dan bahasa Indonesia, serta sebagai pendukung sastra daerah dan sastra Indonesia. Sebagai sarana pendukung bahasa Indonesia, bahasa daerah memiliki peran yang dominan dalam memperkaya kosakata bahasa Indonesia.

Kosakata merupakan salah satu khazanah kebahasaan yang sarat makna. Apabila sebuah bahasa tidak memiliki sebuah konsep tentang sesuatu tetapi terdapat dalam bahasa lain, kata itu merupakan salah satu bentuk bahasa yang dipinjam untuk menghadirkannya.

\section{Bangsa Indonesia merupakan} bangsa yang multikultural, terdiri atas beragam suku dengan budaya dan bahasa daerahnya masing-masing. Keragaman budaya dan bahasa daerah ini merupakan khazanah yang sangat potensial bagi pemerkayaan kosakata bahasa Indonesia. Berdasarkan laporan hasil penelitian Kekerabatan dan Pemetaan Bahasa-Bahasa di Indonesia yang dilakukan oleh Badan Bahasa pada tahun 2008, telah berhasil diidentifikasi sejumlah 442 bahasa. Hingga tahun 2011, tercatat terjadi penambahan sejumlah 72 bahasa sehingga jumlah keseluruhannya menjadi 514 bahasa. Jumlah tersebut masih dapat bertambah karena masih ada beberapa daerah yang belum diteliti. Penyerapan kosakata bahasa daerah, terutama kosakata budaya, merupakan suatu usaha yang harus didukung dalam usaha pengembangan bahasa Indonesia. Dukungan tersebut layak diberikan karena ternyata banyak sekali konsep yang berasal dari kosakata bahasa daerah yang tidak dapat ditemukan dalam konsep bahasa Indonesia dan kalaupun ada, bentuknya biasanya berupa frasa. Selain itu, kosakata bahasa daerah juga memiliki ungkapan yang berisi nilai-nilai kearifan lokal yang biasanya hanya dapat dijumpai dalam bahasa tertentu (Sugono, 2003).

\section{KBBI Pusat Bahasa Edisi Keempat}

(2008) memuat kurang lebih 70 bahasa daerah yang telah dianggap sebagai warga bahasa Indonesia. Jika dilihat dari jumlah entri yang terdapat dalam KBBI Edisi Keempat (2008) yang memuat 90.049 entri, bahasa daerah ternyata hanya memberikan kontribusi sebesar lebih kurang 3,99\% dalam kosakata bahasa Indonesia. Jumlah tersebut sungguh sangat kecil. Oleh karena itu, upaya pengayaan kosakata bahasa Indonesia dengan kosakata bahasa daerah merupakan salah satu upaya yang perlu dipertimbangkan, sehingga bahasa 
daerah dapat berfungsi sebagai pilar utama dan penyumbang terbesar kosakata bahasa negara, seperti yang tersurat dalam Peraturan Menteri Dalam Negeri Nomor 40 Tahun 2007.

Kosakata bahasa daerah yang diserap ke dalam bahasa Indonesia, khususnya $K B B I$, berkenaan dengan berbagai ranah, di antaranya adalah ranah budaya dan tradisi. Salah satu kekayaan bahasa dalam budaya dan tradisi daerah yang sangat potensial untuk memperkaya kosakata bahasa Indonesia adalah budaya dan bahasa Flores. Novel "Suara Samudra, Catatan dari Lamalera", karya Maria Matildis banda ini, mengangkat tema klise yang seringkali muncul dan diangkat dalam novelnovel Indonesia, tentang hubungan dua anak manusia yang tak direstui karena perbedaan status sosial. Novel ini menjadi menarik, manakala ditulis dengan latar desa, tradisi dan budaya nelayan dan penangkapan ikan paus secara tradisional di Lamalera. Novel ini merupakan novel etnografis yang menghadirkan tradisi dan budaya Lamalera melalui latar fisik dan budaya nelayan di Lamalera. Maria merangkai tradisi dan falsafah hidup orang-orang Lamalera, khususnya kaum nelayannya. Maria Matildis Banda menyampaikan warna lokal melalui sastra. Bahasa, diksi, dan kekuatannya berbicara dalam dialek lokal memperkaya khazanah sastra Indonesia. Kondisi ini merupakan salah satu alasan pentingnya 'mengadopsi' registerregister dalam novel tersebut ke dalam kosakata bahasa Indonesia, sehingga bahasa Indonesia dapat semakin mengembangkan dirinya agar dapat berperan secara maksimal sebagai sarana komunikasi dalam berbagai ranah pemakainya, serta semakin mantap berperan sabagai bahasa penguat identitas dan karakter bangsa.

Tulisan ini akan mendeskripsikan kosakata budaya dalam tradisi penangkapan koteklema di Lamalera dalam novel "Suara Samudra, catatan dari Lamalera", sebagai salah satu alternatif pengayaan kosakata bahasa Indonesia, sehingga bahasa Indonesia semakin mantap berperan sebagai bahasa politik identitas dan penguat karakter bangsa.

\section{Konsep}

\subsection{Sastra Etnografi}

Sastra dan budaya sering jalinmenjalin dalam bentuk teks. Teks sastra biasanya memuat keragaman budaya. Biarpun berasal dari disiplin yang berbeda, sastra dan budaya memiliki objek yang sama. Keduanya mengambil objek manusia sebagai mahkluk kultural. Bedanya, karya sastra sering melakukan eksplorasi tidak langsung, menggunakan bahasa konotatif, sedangkan budaya cenderung menggunakan bahasa denotatif.

Teks sastra adalah sebuah jaringan kutipan yang melukiskan sejumlah pusat budaya. Lewat sebuah teks sastra pembaca dapat menangkap sebuah budaya yang dikemas di dalamnya. Teks membawa pesan budaya masing-masing etnis. Dengan mempelajari teks sastra, dengan sendirinya pembaca dapat belajar budaya masingmasing etnis. Setiap etnis atau lokal 
memiliki ekspresi budaya lewat sastra. Teks sastra merefleksikan keragaman budaya. Sastra adalah ekspresi kehidupan manusia. Manusia adalah mahkluk yang berbudaya. Oleh karena itu, sebuah teks sastra "harus" dibaca dengan menggunakan kode-kode budaya yang melahirkannya (Endraswara, 2017: 80-86).

\subsection{Tradisi Lisan}

Tradisi lisan adalah segala wacana yang diucapkan atau sistem wacana yang bukan aksara yang mengungkapkan kegiatan kebudayaan suatu komunitas. Wacana tradisi lisan tidak hanya berupa cerita dongeng, mitologi, dan legenda dengan berbagai pesan di dalamnya, tetapi juga mengenai sistem kognitif masyarakat, sumber identitas, sarana ekspresi, sistem religi dan kepercayaan, pembentukan dan peneguhan adat-istiadat, sejarah, hukum, pengobatan, keindahan, kreativitas, asal usul masyarakat, dan kearifan lokal dalam komunitas dan lingkungannya. Pengungkapan kelisanan tersebut disampaikan terutama dengan mengandalkan faktor ingatan. Penutur atau tukang cerita memang mengingat, tidak menghafalkan apa yang akan disampaikannya (Lord, 1976; Sweeney, 1980 dan 1987; Ong, 1982 dalam Sibarani, 2012: 7-8). Tradisi lisan tidak sekadar penuturan, melainkan konsep pewarisan sebuah budaya dan bagian diri kita sendiri sebagai mahkluk sosial. Tradisi lisan tidak hanya kelisanan yang membutuhkan tuturan seperti peribahasa, dongeng, legenda, mantra, dan pantun, tetapi juga bagaimana kelisanan itu diwariskan secara epistemologis untuk apa diwariskan secara aksiologis, siapa yang mewariskan, kepada siapa diwariskan, dan segala hal yang berhubungan dengan konteks kelisanan itu (Sibarani, 2012: 1112). Sweeney menegaskan bahwa pengertian kelisanan dapat sedikit memuaskan apabila dibicarakan dalam konteks interaksinya dengan tradisi tulisan. Dalam kaitan ini, perlu terlebih dahulu diutarakan kekaburan pemakaian istilah oral dan istilah orality. Istilah oral berkaitan dengan suara. Konsep oral dalam arti ini meliputi segala sesuatu yang diujarkan, dengan kata lain, istilah oral tidak berkaitan dengan keberaksaraan atau tidak beraksaranya penutur yang bersangkutan. Istilah orality diartinya sebagai suatu sistem wacana yang tidak tersentuh oleh huru. Implikasi kata lisan dalam pasangan lisan dan tertulis, dan dalam pasangan lisan-beraksara berbeda. Sweeney mengusulkan istilah oracy untuk mencakup pengertian lisan pada pasangan pertama dan istilah orality untuk pasangan kedua. Konsep kelisanan lebih tepat digunakan dalam konteks sistem pengolahan bahan yang mengandalkan huruf (Sweeney, 1987: 2--5). 
2.3 Tradisi Lisan dalam Novel "Suara Samudra, Catatan dari Lamalera" Karya Maria Matildis Banda

Beberapa bentuk tradisi lisan di Indonesia antara lain adalah 1) bahasa rakyat, 2) ungkapan tradisional, 3) pertanyaan tradisional, 4) sajak dan puisi rakyat, 5) cerita prosa rakyat, dan 6) nyanyian rakyat.

Bahasa rakyat merupakan salah satu bentuk tradisi lisan yang wujudnya bisa berupa logat (dialek) bahasa-bahasa Nusantara, misalnya logat bahasa Jawa dari Indramayu yang merupakan bahasa Jawa Tengah yang telah mendapatkan pengaruh dari bahasa Sunda atau logat bahasa Sunda dari Banten, atau logat bahasa Jawa Cirebon, dan bahasa Sunda Cirebon. Bentu lain bahasa rakyat antara lain adalah slang, argot, cant, shop talk, colloquial, sirkumlokusi, nama julukan, gelar kebangsawanan, jabatan tradisional, bahasa bertingkat, onomatope dan onomastis (Danandjaya, 1991: 22-27).

Banyak tradisi lisan yang diresepsi oleh sastrawan modern. Pantun sebagai sastra lisan sering diresepsi oleh penyair modern. Banyak pula cerita pendek yang memanfaatkan tradisi lisan. Misalnya, geguritan banyak digunakan oleh penyair modern untuk mempermanis sajaknya (Endraswara, 2017: 72-73).

Novel karya Maria Matildis Banda yang berjudul "Suara Samudra, Catatan dari Lamalera", kaya akan bahasa rakyat yang berupa istilah-istilah khusus yang berkaitan dengan tradisi nelayan di Lamalera, khususnya tradisi penangkapan ikan paus. Novel yang mengangkat tema klise, kasih tak sampai ini, menjadi menarik ketika Maria Matildis Banda mengemasnya dalam lokalitas Flores yang eksotis dengan menghadirkan setting sosial masyarakat nelayan Lamalera dengan tradisi penangkapan ikan paus di Lamalera yang penuh warna. Novel ini sarat dengan seting tradisi nelayan Lamalera, dengan istilahistilah khusus yang digunakan oleh nelayan Lamalera, khususnya dalam tradisi penangkapan ikan paus di Lamalera. Istilah-istilah khusus tersebut merupakan salah satu khazanah kekayaan Indonesia yangdapat digunkan sebagai salah satu alternatif pengayaan kosakata bahasa Indonesia, sehingga bahasa Indonesia semakin mantap berperan sebagai bahasa politik identitas dan penguat karakter bangsa.

Bahasa lisan dalam masyarakat dikembangkan dalam hubungan intim dan melalui tatap muka. Dalam wacana lisan ini, kesadaran kata sebagai entitas yang terpisah sangat terbatas. Sebaliknya, dalam bentuk tulis, kata-kata dapat menghidupkan suasana, sehingga proses ini juga disebut sebagai dekontekstualisasi wacana. Menulis merupakan usaha mempertahankan tradisi budaya tempat individu berasal (Endraswara, 2017: 68-69). 
Tradisi lisan sangat rentan dengan perubahan, sehingga pengangkatan setting budaya yang berupa tradisi lisan ke dalam bentuk teks seperti yang terdapat dalam novel "Suara Samudra, Catatan dari Lamalera" ini merupakan salah satu wujud pelestarian budaya yang banyak memberikan manfaat.

\section{Metodologi Penelitian}

Penelitian ini adalah penelitian studi pustaka. Dalam penelitian studi pustaka, pengumpulan data dilakukan melalui penelaahan terhadap berbagai buku, literature, catatan, serta berbagai laporan yang berkaitan dengan masalah yang ingin dipecahkan (Nazir, 1988). Studi pustaka merupakan penelitian yang dilakukan oleh peneliti dengan mengumpulkan sejumlah buku-buku, majalah dan sebagainya yang berkaitan dengan masalah dan tujuan penelitian. Buku tersebut dianggap sebagai sumber data yang akan diolah, seperti yang banyak dilakukan oleh ahli sejarah, sastra, dan bahasa (Danial A. R. 2009: 80).

Berkaitan dengan metode penelitian, sumber data penelitian dalam tulisan ini adalah novel "Suara Samudra, Catatan dari Lamalera" karya Maria Matildis Banda. Data yang digunakan dalam penelitian adalah kosakata budaya dalam tradisi penangkapan ikan paus di Lamalera. Data kosakata budaya yang berkaitan dengan tradisi penangkapan ikan paus di Lamalera, dikumpulkan dari novel
"Suara Samudra, Catatan dari Lamalera". Register-register dalam penangkapan koteklema di Lamalera dalam novel "Suara Samudra, Catatan dari Lamalera", selanjutnya dipilih untuk menentukan register yang dapat digunakan sebagai alternatifmemperkaya kosakata bahasa Indonesia. Langkah berikutnya adalah melakukan deskripsi singkat berkaitan dengan arti kosakata tersebut dalam bahasa Indonesia.

\section{Pembahasan}

\subsection{Latar Belakang Budaya dan Sejarah Flores Timur}

Secara geografis, Lamalera, seting wilayah yang ditampilkan dalam novel "Suara Samudra, Catatan dari Lamalera" termasuk wilayah Flores Timur. Dalam kesadaran masyarakat Flores yang dipandang sebagai suku asli wilayah ini adalah Ile Jadi (kelompok suku yang dilahirkan dari dalam Gunung Mandiri, dengan Wato Lele dan Lia Nurat sebagai leluhur pertama mereka). Namun, ada juga pandangan bahwa sebelum kelahiran kedua tokoh tersebut, sudah hadir terlebih dahulu orang-orang Paji. Selain suku Paji dan Ile Jadi, orang-orang Flores Timur membedakan dua suku migrant, yaitu suku Tena Mau dan suku Sina Jawa. Kelompok Tena Mau adalah kelompok pendatang dari wilayah Nusantara bagian Timur, sementara itu kelompok Sina Jawa adalah 
kelompok pendatang yang berasal dari berbagai wilayah Nusantara bagian Barat. Sina Jawa tidak identik dengan Pulau Jawa, melainkan tempat-tempat dari kepulauan Nusantara bagian barat.

Selain kedua suku tersebut, wilayah Pulau Timor juga didiami orang Sina Mutin Malakkan (Cina Putih Malaka). Mereka menetap di Larantuka dan menurunkan raja dan penduduk Larantuka. Pengaruhpengaruh luar yang "membangun” budaya Flores antara lain adalah pengaruh Jawa, yang diduga berasal dari masa Hindu, diperkirakan sejak abad ke-13. Pada abad ke-16 masuklah pengaruh Bugis dan Makasssar, sementara itu pengaruh Ambon Maluku masuk pada abad ke-17. Pada abad ke-17 juga masuk pengaruh Melayu dan Portugis ke wilayah ini. Bahasa melayu Larantuka masih digunakan sampai saat ini, dan agama Katolik yang disebarkan oleh Portugis masih berkembang sampai sekarang.

Dari segi linguistik, masyarakat Flores Timur dikelompokkan ke dalam lima suku asli Lamaholot, yaitu Lamaholot Barat, Lamaholot Tengah, Labala, dan Kedang.

Pada masa lampau, sistem pengelompokan kampung di Flores timur didasarkan pada suatu tradisi adat wilayah yang membentuk sebuah distrik yang disebut kakang. Organisasi kakang dibentuk dan ditetapkan oleh Raha sira
Demong Pagong Molang. Raja ini dikenal sebagai raja pertama kerajaan Larantuka karena dialah yang meletakkan dasar pemerintahan dan penataan kerajaan. Kakang-kakang tersebut adalah kakang hadung, kakang Lamalera, kakang Boleng, kakang Horowura, kakang Pamakayo, kakang Lewolein, kakang Wolo, Mudakaputu, Lewingo, dan Lewotobi. Selain wilayah kakang, wilayah Flores pada masa lampau juga mengenal wilayah watan.

Secara demografis, penduduk Flores Timur sangat majemuk, dilihat dari segi bahasa, asal-usul, filsafat dan pandangan hidupnya. Tidak jarang pluralitas dan heterogenitas masyarakatnya ini menimbulkan konflik-konflik kepentingan, bahkan pertentangan dan peperangan. Meskipun demikiam, masyarakat Flores dapat membentuk sebuah komunitas sosial budaya dengan pranata-pranatanya yang mampu menjamin rasa aman dan menciptakan persatuan dan kesatuan masyarakatnya (Yapi Taum, 1997: 4-14).

\subsection{Sekilas tentang Bahasa Flores dan}

\section{Dialek Lamalera}

Kabupaten Flores Timur sebagai suatu daerah adsministratif tidak memperlihatkan adanya kesatuan linguistik sebagaimana halnya dengan beberapa wilayah kabupaten di Pulau Flores, seperti Sikka, Ende-Lio. Sekurang-kurangnya 
terdapat empat kelompok bahasa di seluruh wilayah Flores Timur ini. Keempat kelompok bahasa itu adalah bahasa Melayu, bahasa Boru-Hewa, bahasa Kedang, dan bahasa Lamaholot. Bahasa Melayu dituturkan oleh penduduk kota Larantuka, Konga dan Wureh di Pulau Adonara, sedangkan bahasa Hewa-Boru dituturkan oleh beberapa penduduk desa di daerah perbatasan dengan Kabupaten Sikka. Bahasa Kedang dituturkan oleh penduduk di ujung timur pulau Lembata sebelah Timur. Salzner dan Esser menamakan bahasa-bahasa yang terdapat dalam wilayah Kabupaten Flores Timur tersebut sebagai bahasa Solor (Keraf, 1978: 5).

Dialek Lamalera merupakan sebuah dialek yang dipergunakan penduduk desa Lamalera yang terletak di pantai selatan Pulau lembata. Dialek Lamalera ini merupakan salah satu dari bahasa Lamaholot. Dari sekian banyak dialek/bahasa Lamaholot, dialek Lamalera memperlihatkan identitas sendiri berupa fonem-fonem tertentu, di samping struktur morfologis dan perbendaharaan kata yang khas, bila dibandingkan dengan dialekdialek atau bahasa-bahasa yang ada di sekitarnya. Lamalera merupakan pusat pengembangan keagamaan di Pulau Lembata yang secara resmi ditetapkan sebagai paroki pada tahun 1921. Penyampaian pengajaran dan ibadah keagamaan disampaikan dengan menggunakan dialek Lamalera di seluruh pulau. Bahkan dialek Lamalera digunakan dalam buku kebaktian Soedoe Hormat yang digunakan semua gereja di Lembata. Meskipun tidak menjadi bahasa standart di Flores Timur, selama puluhan tahun dialek Lamalera memegang peranan yang sangat penting sebagai bahasa resmi dalam bidang keagamaan, termasuk di daerah Kedang di ujung Timur Lembata yang secara linguistik termasuk dalam keluarga bahasa lain (Keraf, 1978: 1-2).

\subsection{Tradisi Penangkapan Ikan Paus di Lamalera}

Desa Lamalera yang bersuku Lamaholot terletak di antara bukit batu dan cadas. Wilayah ini secara adsministratif termasuk dalam Kabupaten Pulau Lembata. Secara geografis wilayah ini terletak di hadapan ke Laut Sawu.Desa Lamalera ini terkenal dengan tradisi penangkapan ikan pausnya, yang dalam bahasa Lamalera disebut sebagai koteklema.

Tradisi penangkapan paus oleh masyarakat di Desa Lamalera, Kecamatan Wulandoni, Kabupaten Lembata ini telah berlangsung sejak lama, sejak nenek moyang suku Lamalera menempati daerah tersebut. Kebiasaan memburu paus sudah dimulai sejak abad ke-17 atau mungkin ke16. Catatan Portugis menyebutkan adanya 
masyarakat di Lembata yang mencari paus dengan cara tradisional.

Perburuan ikan paus dilakukan oleh penduduk pria Lamalera yang sudah dewasa, serta dianggap memiliki kemampuan (biasanya setiap keluarga mewakilkan satu anggota keluarganya). Sebelum berburu, mereka semua memanjatkan doa-doa kepada Tuhan agar diberi keberhasilan dalam perburuan ikan paus.

Perburuan paus biasanya dimulai pada bulan Mei. Perburuan dilakukan menggunakan perahu yang terbuat dari kayu yang disebut "peledang." Orang yang bertugas menikam paus disebut lamafa. Seorang lamafa berdiri diujung perahu dan untuk menikam paus.Lamafaakan melompat dan menikamkan tombak "tempuling" pada paus.Seorang lamafa, juru tikam yang memimpin kawanan matros atau pendayung, siap memberi aba-aba meluncurkan peledang, perahu penangkap paus yang khusus dibuat. Para nelayan menunggu seseorang menyerukan Baleo! Baleo! Seruan tersebut merupakan pertanda ikan paus muncul di permukaan laut yang biasanya berlangsung di antara bulan-bulan penangkapan, yaitu Mei dan Oktober. Pemburuan dapat memakan waktu berjam-jam. Saat paus nampak, matros akan mengayuh dayung ke arah paus sasaran. Lamafa segera menghujamkan tempuling ke jantung sang paus, tiga hingga empat kali sampai paus letih kehabisan darah. Hujaman pertama dapat sangat berbahaya bagi seluruh awak, karena paus akan menerjang, bergeliat kesakitan dan menghancurkan segala yang ada di dekatnya.Ikan Paus Sperma adalah buruan satu-satunya yang dijalankan masyarakat Lamalera Atas ataupun Lamalera Bawah. Ikan paus biru (Balaenoptera musculus) pun sering berlalu di hadapan mereka sebagai mamalia air terbesar yang ada (cetacean). Namun, paus itu tidak pernah diburu, karena selain untuk menjaga kelestarian satwa laut besar ini, tradisi menyebutkan bahwa Lamalera dan Lembata pada umumnya pernah diselamatkan paus biru dulu kala. Pantangan lain bagi mereka selain membunuh ikan paus biru, ialah membunuh paus sperma betina yang sedang hamil, anak paus, dan paus yang sedang dalam suasana kawin. Kepekaan terhadap kondisi ini hanya dapat diturunkan oleh klan-klan yang ada di Lamalera.

Secara tradisi, ikan paus yang didapat dikonsumsi untuk masyarakat desa dan tidak melebihi dari kebutuhan hidup secara keseluruhan secara sosial. Terkadang jumlah paus yang ditangkap berfluktuasi sesuai ketersediaan dan keperluan masyarakatnya.

Daging paus yang diperoleh dari perburuan ini nantinya akan dibagikan kepada seluruh penduduk sesuai besar 
kecilnya jasa wakil anggota keluarga mereka dalam proses perburuan pausnya. Selain hasil daging, masyarakat juga memanfaatkan minyak paus sebagai minyak urut, bahan obat dan bahan bakar untuk pelita atau lampu teplok.

\subsection{Register-register dalam Tradisi Penangkapan Ikan Paus di Lamalera sebagai Kosakata yang Berpotensi untuk Memperkaya \\ Kosakata Bahasa Indonesia}

Register secara sederhana dapat dikatakan sebagai variasi bahasa berdasarkan penggunaannya, sedangkan dialek sebagai variasi bahasa berdasarkan penggunanya. Di dalam konsep ini, register tidak terbatas pada pilihan kata saja (seperti pengertian register dalam teori tradisional), tetapi juga termasuk pada pilihan penggunaan struktur teks dan teksturnya: kohesi dan teksikogramatika, serta pilihan fonologi atau grafologinya. Karena register meliputi seluruh pilihan aspek kebahasaan atau linguistik, banyak linguis menyebut register sebagai style atau gaya bahasa.

Pada mulanya register digunakan oleh kelompok-kelompok profesi (pekerjaan) tertentu. Bermula dari adanya usaha orang-orang yang terlibat dalam komunikasi secara cepat, tepat, dan efisien di dalam suatu kelompok kemudian mereka menciptakan ungkapanungkapan khusus. Setiap anggota kelompok itu beranggapan sudah dapat saling mengetahui karena mereka samasama memiliki pengetahuan, pengalaman, dan kepentingan yang sama.

Akibat dari interaksi semacam itu, akhirnya bentuk tuturan (kebahasaannya) akan menunjukkan ciri-ciri tertentu, misalnya pengurangan struktur sintaktik, pembalikan urutan kata yang normal dalam kalimat (Holmes, 1992:276-282). Oleh sebab itu, ciri-ciri tuturan (kebahasaan) mereka selain akan mencerminkan identitas kelompok tertentu, juga dapat menggambarkan keadaan apa yang sedang dilakukan oleh kelompok tersebut.

Konsep register secara lebih sempit, yakni hanya mengacu pada pemakaian kosakata khusus yang berkaitan dengan kelompok pekerjaan yang berbeda. Sementara itu, Wardaugh (1986:48), memahami register sebagai pemakaian kosakata khusus yang berkaitan dengan jenis pekerjaan maupun kelompok sosial tertentu. Misalnya, pemakaian bahasa para pilot, manajer bank, para penjual, para penggemar musik jazz, perantara (pialang), dan sebagainya.

Berikut ini adalah register-register dalam penangkapan koteklema di Lamalera dalam novel "Suara Samudra, Catatan dari Lamalera" yang dapat digunakan sebagai alternatifuntuk memperkaya kosakata bahasa Indonesia. 


\section{Koteklema}

Ikan paus berjenis sperm (physeter macrocephalus) yang biasa dan boleh ditangkap oleh nelayan Lamalera. Kotlekema merupakan bahasa Lamalera untuk menyebut ikan paus. Salah satu jenis ikan paus yang terdapat di perairan Lamarlera adalah ikan paus jenis seguni (killer whale). Ikan paus jenis ini boleh ditangkap oleh nelayan Lamalera. Kotlekema yang tidak boleh ditangkap adalah kelaru karena jenis ini dianggap sebagai ikan paus pemandu (SS: 8)

\section{Baleo}

Berasal dari kata ba: pikul atau baa dan leo: tali leo. Gabungan kata baleo memiliki arti pikul atau membawa tali leo. Baleo dalam bahasa masyarakat nelayan di Lamalera merupakan ungkapan yang digunakan untuk mengatakan bahwa ada ikan paus di laut. Ketika kata baleo diserukan, nelayan Lamalera akanmemahami bahwa hal itu merupakan ajakan untuk segera turun ke laut, bersiap-siap melaut karena ada ikan paus yang datang. Mendengar kata baleo yang diserukan berkali-kali, sambungmenyambung, nelayan yang terdiri atas matros (pendayung), lama uri (juru mudi), lamafa (tukang tikam ikan paus), breung alep (pendamping lamafa), dan semua pihak yang terlibat dengan peledang akan segera menyiapkan diri (SS: 9)

\section{Hamma Lolo}

Bagian haluan peledang yang menonjol ke depan. Hamma lolo merupakan tempat seorang lamafa berdiri, mengambil ancang-ancang untuk menikam ikan paus(SS: 9)

\section{Peledang}

Perahu nelayan yang digunakan untuk melaut/menangkap ikan (SS: 9).

\section{Lamafa}

Nelayan yang bertugas menikam kotlekema (ikan paus). Seorang lamafa adalah seorang laki-laki pilihan. Ada tiga kriteria yang harus dipenuhi agar seorang dapat menjadi lamafa, yaitu garis keturunan lamafa, kemampuan untuk bertanggung jawab sebagai lamafa, dan ketrampilan. Pada masa sekarang, seorang lamafa tidak selalu ditentukan oleh faktor keturunan, tetapi lebih pada keterampilan yang dimilikinya, sehingga ia layak menjadi lamafa (SS: 16)

\section{Kaffe Numung}

Tempuling berbentuk tanda centang dengan salah satu bagian terbuka lebih tinggi. Bermata tajam yang berfungsi untuk menikam ikan di laut (SS: 16)

\section{Naje}

Merupakan bangunan pondok beratap yang dibuat dengan dinding separuhnya dari bambu atau kayu. Bangunan ini merupakan tempat peledang bernaung apabila tidak sedang melaut. Bangunan ini biasanya didirikan sekitar 100 meter dari bibir pantai (SS: 17)

8. Bero

Perahu untuk penumpang (SS: 56)

9. Gili Kajo

Pemotongan kayu yang akan digunakan sebagai bahan perahu (SS: 57).

10. Leva Nuang

Musim penangkapan ikan, termasuk ikan paus. Musim leva nuang biasanya berlangsung pada bulan Mei sampai dengan Oktober. Musim leva nuang biasanya dibuka dengan perayaan ekaristi syukur pada tanggal $1 \mathrm{Mei}$ setiap tahunnya, dan ditutup dengan perayaan syukur pula pada setiap tanggal 31 Oktober (SS: 59-60).

\section{Pneta Alep}

Merupakan mata pencaharian khusus kaum perempuan istri nelayan. Pneta alep biasanya berupa penukaran atau barter bahan pangan dengan ikan yang dilakukan oleh istri-istri atau keluarga perempuan nelayan di Lamalera (SS: 62) 


\section{Pau Laba Ketilo}

Ritual persembahan yang dilakukan pada saat pembuatan sebuah perahu. Persembahan ini berupa pemberian makan kepada semua peralatan yang akan dipakai selama pembuatan perahu (SS: 66)

13. Breung Alep

Pembantu lamafa pada saat beraksi di tengah lautan (SS: 67)

14. Lama Uri

Juru mudi peledang (SS: 67).

15. Matros

Pendayung perahu (bahasa Lamalera) (SS: 67)

16. Tale leo

Tali khusus yang digunakan untuk menghubungkan tempuling dan lambung peledang (SS: 68)

17. Ata Mola

Ata mola adalah tukang yang membuat perahu (SS: 68)

18. Lamalera

Lamalera adalah nama sebuah wilayah di Flores Timur, terdiri atas dua kata, lama yang artinya piring dan lera yang artinya matahari, lamalera secara keseluruhan memiliki arti piring matahari (SS: 75).

19. Fekka Meggu

Ritual pembagian potongan-potongan daging ayam yang dilakukan oleh para lelaki untuk lelaki yang terlibat dalam pembuatan peledang (SS: 92).

20. Tena

Perahu peledang yang sudah turun ke laut (SS: 93)

\section{Tena Laja}

Perahu layar (SS: 93). Tena memiliki arti perahu yang berlayar mencari nafkah di laut. Tena laja sama dengan peledang pada saat sudah difungsikan di laut (SS: 97)

22. Ola Nua

Mencari nafkah di laut (SS: 112).

23. Lolalita

Arena pantai pada bagian barat, tempat persiapan sebelum melaut (SS: 136)

\section{Blaku}

Pembagian daging ikan paus untuk para pendorong perahu menuju ke laut (SS: 137)

25. Panno Leo

Penggabungan serat benang (mora) menjadi delapan sampai sepuluh urat serat sebelum dipintal untuk dijadikan tale leo (SS: 142)

26. Keduke Lelu

Benang hasil pintalan (SS: 150)

27. Mora

Gulungan keduke lelu (SS: 150)

28. Kela

Wadah tempat meletakkan mora (SS: 150)

29. Pnete

Kegiatan barter/tukar-menukar ikan paus hasil tangkapan para nelayan dengan ubi-ubian, sayuran dan lainnya yang merupakan hasil bumi penduduk pegunungan/pedalaman. Pnete ini dilakukan dengan berkeliling dari rumah ke rumah dalam suasana kekeluargaan (SS: 156)

30. Fule

Barter ikan paus dengan sayur, jagung, ubi, kacang-kacangan atau sejenisnya yang berlangsung di pasar. Pada umumnya fule berlangsung secara kekeluargaan saat perempuan nelayan dari Lamalera datang membawa ikan paus, dan perempuan yang tinggal di pedalaman/pegunungan membawa hasil bumi/pertanian. Mereka akan saling menukar hasil laut dan hasil bumi untuk memenuhi kebutuhan akan pangan (SS: 157)

31. Kerakki

Bagian dari hamma lollo yang merupakan tempat lamafa duduk sebelum atau sesudah beraksi sebagai lamafa (SS: 163)

32. Seguni

Jenis ikan paus yang boleh ditangkap tetapi sering dihindari oleh nelayan Lamalera (SS: 163). Paus jenis ini merupakan paus pembunuh atau orca. Jenis paus ini secara tradisional 
dilarang untuk dibunuh oleh nelayan Lamalera (SS: 175)

\section{Temu Bela}

Kotlekema, seguni, temu, temu bela adalah beberapa jenis ikan paus yang dikenal nelayan Lamalera. Kotlekema merupakan nama lokal untuk ikan paus jenis sperm wale, seguni adalah nama lokal untuk jenis ikan paus killer wale, temu merupakan nama lokal untuk jenis dolphin, dan temu bela untuk jenis pilot whale (SS: 172-173)

34. Pemali

Pantangan. Nelayan Lamalera pantang menangkap ikan paus yang sedang menyusui, paus bayi dan anak, paus yang sedang hamil ataupun paus yang masih muda (SS: 173)

35. Kea

Paus yang mendekat pada paus yang kena tikam. Peristiwa ini terlihat sebagai ritual yang dilakukan oleh ikan paus ketika menyaksikan ikan paus lainnya tertangkap oleh nelayan, sebagai tanda perpisahan dan ucapan selamat tinggal. Kotlekema yang tidak tertikam biasanya akan menyentuh peledang yang membawa kotlekema yang tertangkap dengan cara menyentuh peledang secara perlahan dengan mulutnya, sebelum peledang melanjutkan perjalannnya (SS: 175)

36. Blettu

Topi tradisional yang terbuat dari daun lontar. Biasa dibawa nelayan ke laut untuk menghindari panas terik. Blettu juga berfungsi untuk memberi tanda bahwa mereka memerlukan bantuan karena berada dalam ancaman bahaya. Jika nelayan melihat topi di atas tiang bambu, mereka segera mendekat untuk memberikan pertolongan (SS: 197).

37. Hadek blettu

Mengangkat tiang bambu yang di atasnya terletak blettu. Hal ini dilakukan untuk meminta pertolongan apabila nelayan mengalami masalah di tengah laut. Ungkapan lain yang biasa digunakan adalah Hedek Klala (SS: 200)

38. Faja koda kiri

Tradisi mengikat sejenis batu (menjadi batu elu) dan menenggelamkannya di tengah laut. Tali ditarik kembali beberapa saat kemudian untuk melihat apakah ada darah pada batu elu. Sebuah kepercayaan tradisi bahwa darah di batu elu merupakan isyarat adanya bencana kematian di tengah laut (SS: 212)

39. Tlake

Galah dari bamboo, salah satu alat penikam ikan (SS: 215)

40. Buri

Sejenis terompet dari kulit kerang. Suaranya nyaring jika ditiup. Suara ini memberi tanda adanya peristiwa tertentu di laut, tanda untuk menunjuk arah, memohon pertolongan, atau tanda lainnya yang menghubungkan peledang yang mengalami masalah dengan peledang lainnya (SS: 224)

41. Duri

Sejenis pisau yang berujung lancip berfungsi untuk menikam (SS: 226)

42. Koteklema koro

Awan pada malam bulan terang. Awan ini berbentuk dada ikan paus, yang menjadi tanda alam bahwa ada ikan paus yang akan melewati perairan Laut Sawu di depan pantai Lamalera (SS: 260)

43. Kofa laki

Gumpalan awan yang berserakan di langit pada malam hari. Di antara gumpalan awan tersebut dapat ditemukan kotlekema horok bagi yang memiliki penglihatan yang jeli (SS: 260)

44. Kara

Pikulan berisi dendeng ikan untuk ditukar dalam pasar barter di pasar Wulan Doni di Lamalera (SS: 357) 


\section{Penutup}

Kosakata bahasa daerah merupakan sumber dan benih pengembangan kosakata bahasa Indonesia. Penyerapan kosakata bahasa daerah bermanfaat untuk pemekaran dan pemerkayaan bahasa Indonesia serta untuk pengembangan bahasa daerah itu sendiri. Salah satu bahasa daerah yang memiliki kosakata khas adalah bahasa nelayan di Lamalera. Mereka memiliki register-register khusus yang berkaitan dengan tradisi penangkapan ikan paus.

$$
\text { Usaha penyerapan kosakata }
$$

tersebut tentunya harus diikuti dengan kodifikasi sehingga nantinya akan tercipta keteraturan bentuk yang sesuai dengan kaidah pemakaian bahasa Indonesia. Salah satu bentuk produk kodifikasi itu ialah Kamus Besar Bahasa Indonesia (KBBI). KBBI juga menjadi penting karena kamus itu dibuat oleh lembaga pemerintah dan dipakai sebagai acuan oleh masyarakat.

\section{Daftar Pustaka}

Alwi, Hasan dan Dendy Sugono. (2003). Politik Bahasa: Rumusan Seminar Politik Bahasa. Jakarta: Pusat Bahasa, Departemen Pendidikan Nasional.

Alwi, Hasan dan Dendy Sugono. (2001). Politik Bahasa. Jakarta: Badan Pengembangan dan Pembinaan Bahasa, Kementerian Pendidikan dan Kebudayaan.
Danandjaya, James. (1991). Folklor Indonesia, Ilmu Gosip, Dongeng, dan Lain-lain. Jakarta: Penerbit Grafiti.

Danial AR, Endang. (2009). Penulisan Karya Ilmiah: Salah Satu Panduan untuk Mahasiswa dan Guru PPKN dalam Mengembangkan Profesi melalui Karya Tulis Ilmiah. Bandung: Ath-Toyyibiyah.

Endraswara, Suwardi. (2015). Metodologi Penelitian Antropologi Sastra. Yogyakarta: Penerbit Ombak.

Fernandez, Inyo Yos. (1996). Relasi historis Kekerabatan Bahasa Flores, Kajian Linguistik Historis Komparatif Terhadap Sembilan Bahasa di Flores. Ende: Penerbit Nusa Indah.

Keraf, Gregorius. (1978). Morfologi Dialek Lamalera. Ende-Flores: Percetakan Offset Arnoldus.

Matildis Banda, Maria. (2017). Suara Samudra, Catatan dari Lamalera. Yogyakarta: Penerbit PT Kanisius.

Nazir, Moh. (1988). Metode Penelitian. Jakarta: Penerbit Ghalia Indonesia.

Yapi Taum, Yoseph. (1997). Kisah Wato Wele-Lia Nurat dalam Tradisi Puisi Lisan Flores Timur. Jakarta: Yayasan Obor Indonesia.

Sugono, Dendy et al. (2008). Kamus Besar Bahasa Indonesia Pusat Bahasa Edisi Keempat. Jakarta: Gramedia Pustaka Utama. 